\title{
Selected metabolites of neutrophils in patients with 2-type diabetes complicated and non complicated with diabetic foot syndrome during colonization of $E$. coli toxin
}

\author{
Tadeusz Łoś1, Kamil Torres ${ }^{1,2}$, Monika Bojarska-Łośn, Anna Torres'2, \\ Grzegorz Staśkiewicz² ${ }^{2}$ Ryszard Maciejewski²,4, Jacek Roliński ${ }^{5}$, Sebastian Radej5, \\ Elizabeth Klimowicz ${ }^{2}$
}

${ }^{1}$ Department of General Surgery, District Specialistic Hospital, Lublin, Poland

${ }^{2}$ Human Anatomy Department, Medical University of Lublin, Poland

${ }^{3}$ Internal Medicine, Endocrinology and Diabetology Department, District Specialistic Hospital, Lublin

${ }^{4}$ Medical Emergency Department, UITM Rzeszów, Lublin, Poland

${ }^{5}$ Department of Clinical Immunology, Medical University of Lublin, Poland

\begin{abstract}
Neutrophils play an important role in the pathogenesis of complications of diabetes mellitus. The aim of the study was to evaluate the metabolism of neutrophiles activation markers during the colonization of $E$. coli endotoxin in order to determine their potential role in the treatment of 2-type diabetes complicated and non-complicated with the diabetic foot syndrome and to evaluate production of peroxide anions by stimulated and non-stimulated neutrophils depending on the exposition time. 54 patients were divided into 3 groups (15 healthy volunteers - control group (1), group $2-17$ patients with 2-type non-complicated diabetes group 3-22 patients with diabetes and diabetic foot syndrome). Blood samples from all subjects were examined. Results show significant differences of E.coli endotoxin influence on metabolism of neutrophiles in study groups. Production of peroxide anions by non-stimulated neutrophils in $20^{\text {th }}$ minute of the experiment was 15 times higher in the group with no diabetic foot and 18 times higher in the group with diabetic foot as compared to the control group. Production of peroxide anions produced by neutrophils increased significantly with the exposure time. The results correspond to data in the literature, that suggest, that type, time of exposition and concentration of pathogens may significantly interfere with neutrophiles activity in the course of diabetes.
\end{abstract}

Key words: E. coli, neutrophiles, diabetes mellitus, diabetic foot

\section{Introduction}

Diabetes is considered as one of the most important health problems of our civilization $[1,2]$. Chronic diabetes complications remain essential in the treatment of this disease. Diabetes and its complications are still a serious social and economic problem. Chronic complications including vascular damage remain essential in the treatment of this disease. The numbers of resources spend on diabetes and diabetic complications are still increasing globally.

Correspondence: G. Staśkiewicz, Human Anatomy Department, Medical University of Lublin, Jaczewskiego 4 Str., 20075 Lublin; tel.: (+48) 609522559, e-mail: grzegorz.staskiewicz@umlub.pl
Neutrophils play an important role in the pathogenesis of diabetes. Despite many scientific researches concerning the function of neutrophiles in both physiological and pathological reactions their function has not been completely explained. However, it is proved that neutrophiles play an important role in the pathogenesis of diabetes. Studies concerning the metabolism of selected markers of neutrophiles activated by E. coli endotoxin in patients with 2-type diabetes complicated and non-complicated by diabetic foot syndrome can be an useful completion.

The aim of the study was to evaluate the metabolism of neutrophils activation markers during the colonization of $E$. coli endotoxin in order to determine their potential role in the treatment of 2-type diabetes 


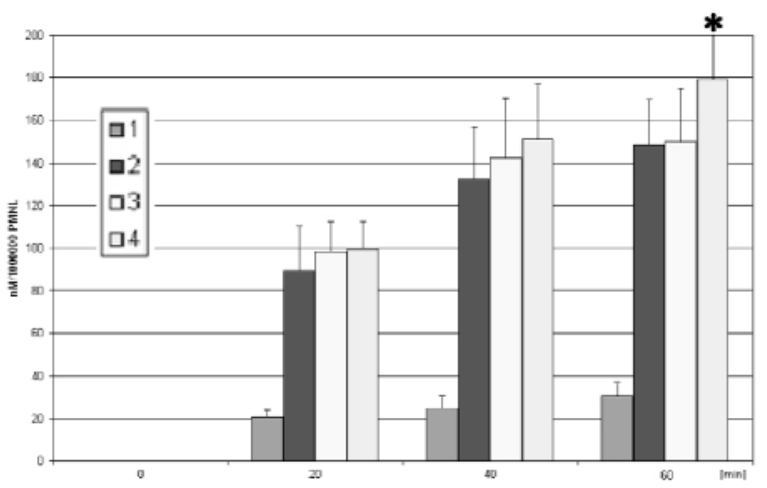

a

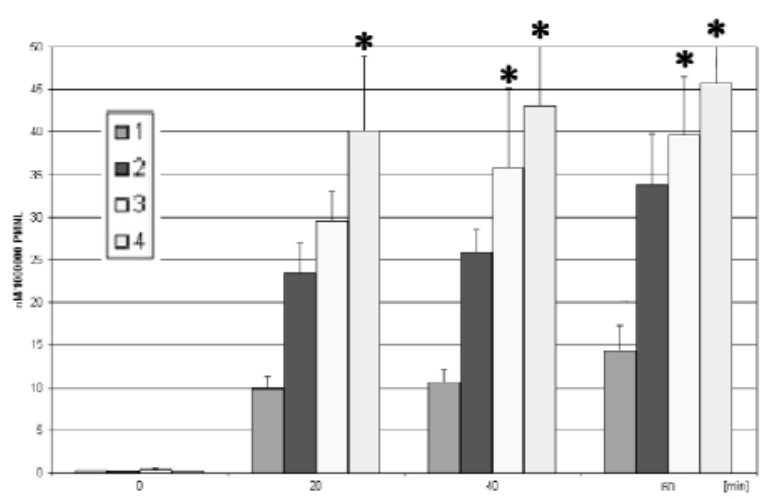

C

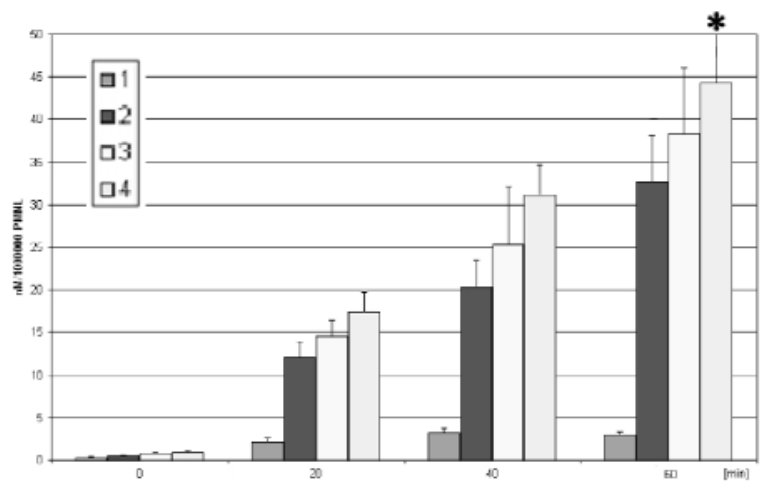

e

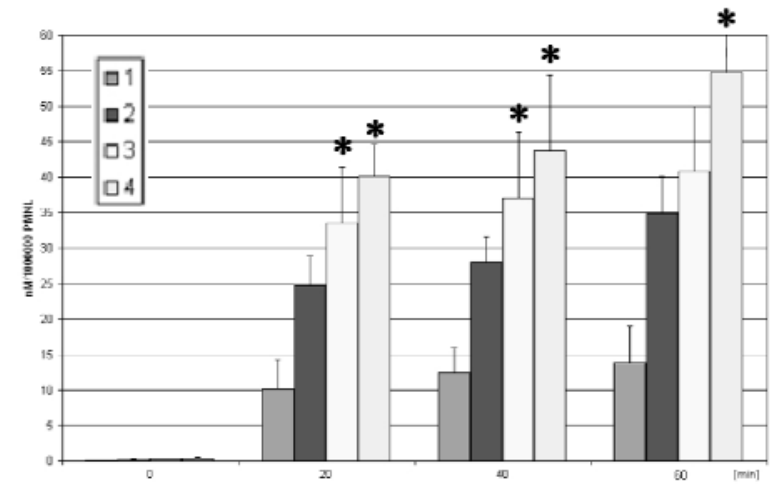

b

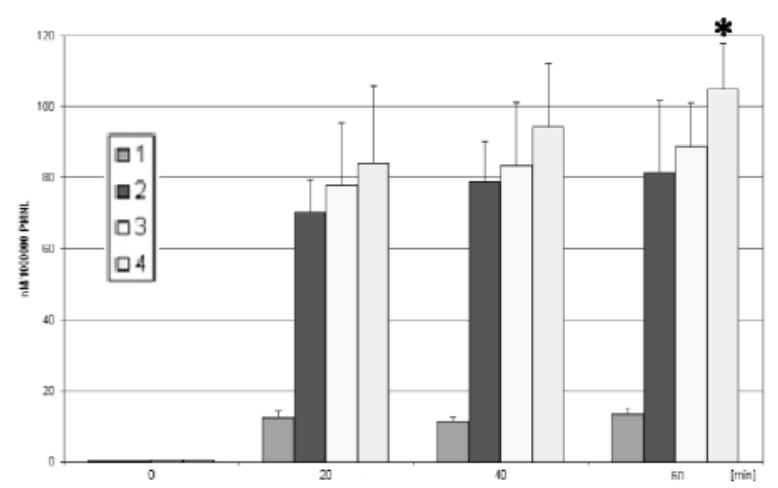

d

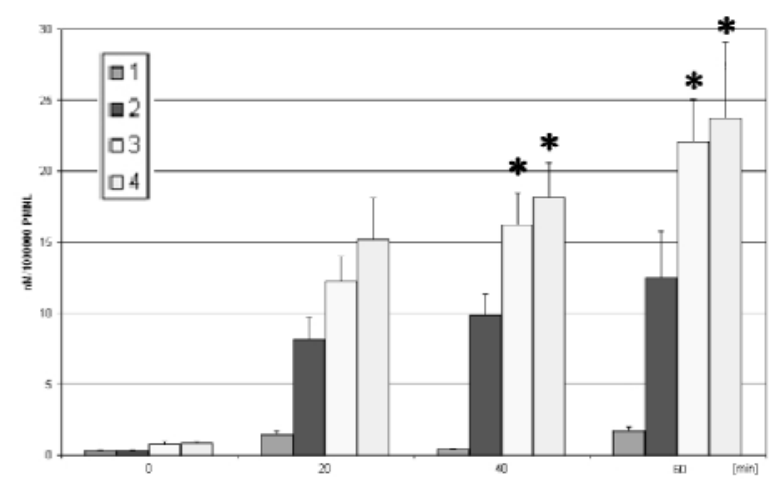

f

Figure 1. Influence of E. coli endotoxin to peroxide anions production by neutrophiles; a. non-stimulated neutrophiles, group 1; b. nonstimulated neutrophiles, group 2; c. non-stimulated neutrophiles, group 3; d. stimulated neutrophiles, group 1; e. stimulated neutrophiles, group 2; f. stimulated neutrophiles, group 3. Bars represent concentrations of E. coli endotoxin: 1: no endotoxin, 2: $1 \mu \mathrm{g} / \mathrm{ml}, 3: 5 \mu \mathrm{g} / \mathrm{ml}$, 4: $10 \mu \mathrm{g} / \mathrm{ml} . *=\mathrm{p}<0.05$ for comparison of peroxide anions production as compared with previous time period, starting with 20 . minute of experiment.

complicated and non-complicated with the diabetic foot syndrome and to evaluate production of peroxide anions by stimulated and non-stimulated neutrophils depending on the exposition time.

\section{Material and methods}

Patients. 54 patients were included into the study. Patients were divided into 3 groups: Group 1 (control group) - 15 healthy vol- unteers (mean age: $45 \pm 9$ years); Group 2 (17 patients) with 2-type non-complicated diabetes (mean fasting blood sugar $98 \mathrm{mg} \%$ ); Group $3-22$ patients with 2-type diabetes complicated with diabetic foot syndrome (mean fasting blood sugar $105 \mathrm{mg} \%$ ). In both experimental groups patients were 45-70 years old (mean age: $57 \pm 13$ years). A $15 \mathrm{ml}$ blood sample was taken from all patients.

Cells. Neutrophils were isolated and activated using Zymosan (Sigma, St. Louis, USA) which was previously opsonizated by autological serum according to Markert et al. [8] method. The sus- 

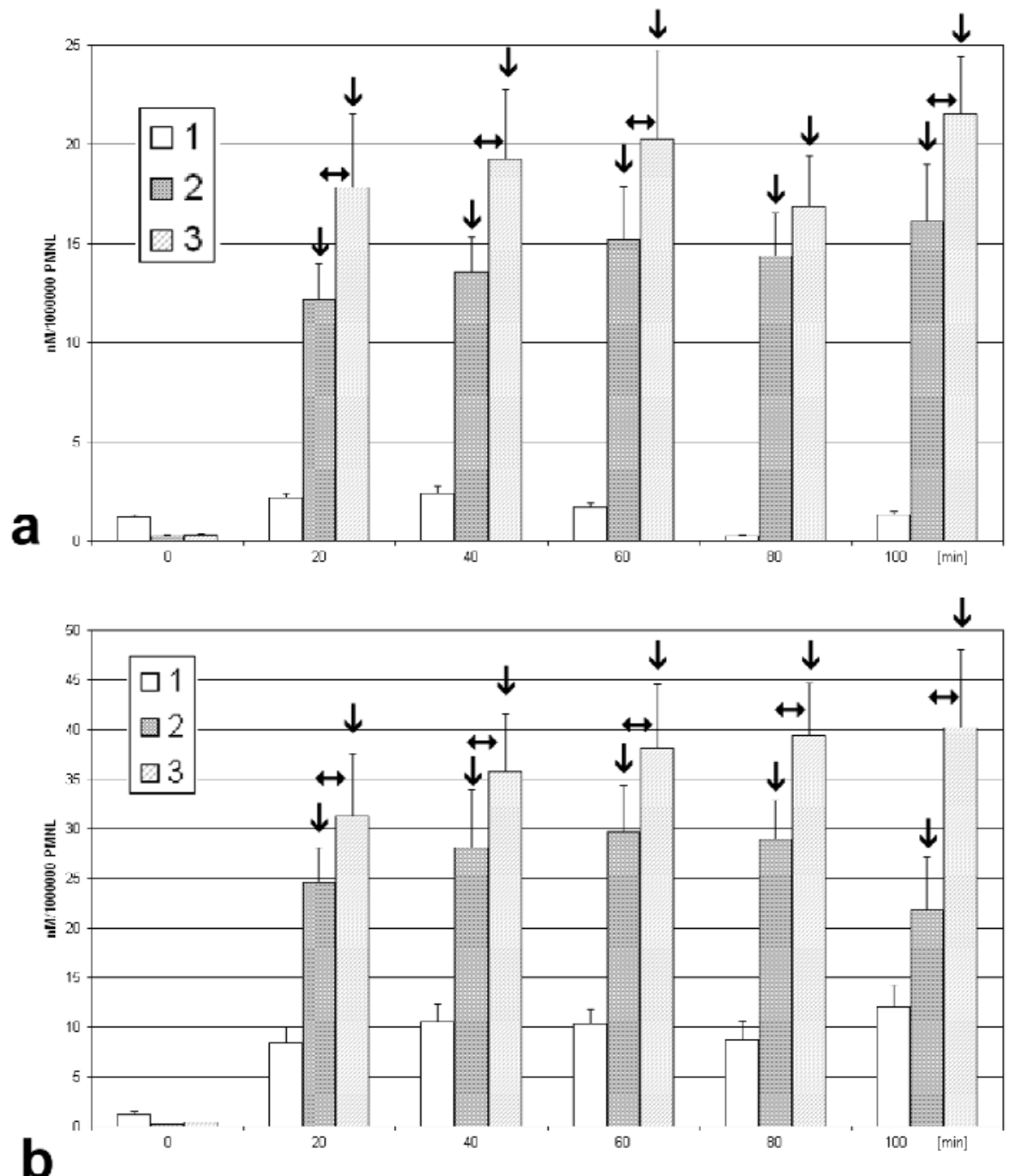

Fig. 2. Production of peroxidase anions (nM/1000000 PMNL) neutrophiles in control group (1) and experimental groups $(2,3)$. $\mathbf{a}-$ non-stimulated neutrophiles. $\mathbf{b}-$ stimulated neutrophiles. $\downarrow=p<0.05$ for differences between experimental groups and group $1 ; \leftrightarrow=\mathrm{p}<0.05$ for differences between experimental groups 2 and 3 . pension of granulocytes was incubated with opsonizated Zymosan. E. coli's endotoxin (0111:B4 type, Difco Corp., Detroit, USA) was added to the solution in doses of $1 \mu \mathrm{g} / \mathrm{ml}, 5 \mu \mathrm{g} / \mathrm{ml}$ and $10 \mu \mathrm{g} / \mathrm{ml}$. The cells were centrifuged after 20, 40 i 60 minutes, and peroxide anions were measured in supernatant according to Johnston et al. [3]. The suspension of granulocytes was incubated with opsonizated Zymosan. Next granulocytes were caused by Hank's balanced salt solution (HBSS- $136 \mathrm{mM} \mathrm{NaCl}, 5.4 \mathrm{mM} \mathrm{KCl}, 0.44 \mathrm{mM}$ $\mathrm{KH}_{2} \mathrm{PO}_{4}, 0.34 \mathrm{mM} \mathrm{Na} \mathrm{HPO}_{4}, 5.6 \mathrm{mM}$ glucose termostated in temp of $37^{\circ} \mathrm{C}$ ) to stick to nylon fibers. Cells which did not stick to the fibers were removed by the abovementioned buffer. Buffer was replaced by another buffer containing demanded stimulator (FMLP $1 \times 10-7 \mathrm{M} / 1$, A23187 2.5 $\mu \mathrm{g} / \mathrm{ml}$, PAF $5 \times 10-6 \mathrm{M} / 1$, LTB4 5×10 -6 $\mathrm{M} / 1$ ) or cytochrome c $5 \times 10-5 \mathrm{M} / 1$ in order to measure the production of peroxide anions.

Statistical analysis. Obtained data was statistically analyzed. Differences between groups were evaluated with t-Student test, $p$ value of $<0.05$ was considered statistically significant.

\section{Results}

Results are presented in Fig. 1 a-f and 2 a-b. In all study groups $E$. coli endotoxin in all concentrations caused significantly $(\mathrm{p}<0.05)$ increased production of peroxide anions since 20. minute of experiment.
E. coli endotoxin caused significantly $(\mathrm{p}<0.05)$ lower production of peroxide anions in diabetic patients study groups 2 and 3 - Fig. 1 b, c, e, f, as compared with control group 1. Time of exposition to E. coli endotoxin caused significantly higher production of peroxide anions in both stimulated and non-stimulated neutrophiles.

\section{Discussion}

E. coli infections may result with serious complications in diabetic patients [3]. The course of E. coli sepsis may also be much more severe in diabetic subjects [4]. It may also influence the course of complications of diabetes, like endophtalmitis [5] or pyelonephritis [6]. Neutrophiles play an important role in the complications of diabetes $[7,8]$.

In the study, a significant influence of $E$. coli endotoxin to metabolic activity of both stimulated and nonstimulated neutrophiles was observed in all groups. Peroxide anions production by neutrophiles increased significantly with time of incubation and dose of endotoxin. It was also observed, that the production was sig- 
nificantly lower in diabetic patients, in both groups 2 and 3 .

The results correspond to data in the literature, that suggest, that type, time of exposition and concentration of pathogenes may significantly interfere with neutrophiles activity in the course of diabetes. Disorders of prooxidants and antioxidants balance can be caused by increased production of prooxidants, deficiency of antioxidants or parallel presence of these phenomenon [9]. This process is known as oxidative stress. It has an important role in the pathomechanism of chronic complications of diabetes [10,11]. The research on modulation of function of neutrophiles in oxidative stress takes place [12].

Production of peroxide anions by non-stmulated neutrophiles was 15-times higher in group 2, and 18times higher in group 3 as compared to control group. In zymosan-stimulated neutrophiles, in 20. minute of experiment, the peroxidase production was 25-times higher and 30-times higher in groups 2 and 3, respectively. This may suggest, that severity of diabetic complications may be related to time of exposition of the patient to unfavourable factor [13].

\section{References}

[ 1] Ludvigsson J. Why diabetes incidence increases- a unifying theory. Ann NY Acad Sci. 2006;1079:374-82.

[ 2] Younes NA, Ahmad AT. Diabetic foot disease. Endocr Pract. 2006;12(5):583-92.

[3] Dima FV, Laky D, Dima SV. Enhanced susceptibility of young rats with alloxan-induced diabetes mellitus to enterohemorrhagic Escherichia coli. Ann NY Acad Sci. 1994;730:310-2.
[ 4] McDonough KH, Barbee RW, Dobrescu C et al. Enhanced myocardial depression in diabetic rats during E. coli sepsis. Am J Physiol. 1987;253:276-82.

[5] Walmsley RS, David DB, Allan RN et al. Bilateral endogenous Escherichia coli endophthalmitis: a devastating complication in an insulin-dependent diabetic. Postgrad Med J. 1996;72: 361-3.

[ 6] Levison ME, Pitsakis PG. Effect of insulin treatment on the susceptibility of the diabetic rat to Escherichia coli-induced pyelonephritis. J Infect Dis. 1984;150(4):554-60.

[ 7] Vucic M, Gavella M, Bozikov V et al. Superoxide dismutase activity in lymphocytes and polymorphonuclear cells of diabetic patients. Eur J Clin Chem Clin Biochem. 1997;35(7): 517-21.

[ 8] Westerhausen M, Meuret G, Senn HJ et al. Bacteriostatic activity of neutrophils and monocytes and their disorders. Haematol Blood Transfus. 1978;21:359-61.

[ 9] Yasunari K, Maeda K, Nakamura M et al. Oxidative stress in leukocytes is a possible link between blood pressure, blood glucose, and C-reacting protein. Hypertension. 2002;39(3): 777-80.

[10] Muchova J, Liptakova A, Orszaghova Z et al. Antioxidant systems in polymorphonuclear leucocytes of Type 2 diabetes mellitus. Diabet Med. 1996;16(1):74-8.

[11] Colak E, Majkic-Singh N, Stankovic S et al. Parameters of antioxidative defense in type 2 diabetic patients with cardiovascular complications. Ann Med. 2005;37(8):613-20.

[12] Łoś T, Torres K, Bojarska-Łoś M et al. The influence of selected cyclooxygenase inhibitors on the production of peroxide anions in neutrophiles of patients with 2-type diabetes complicated and non-complicated by diabetic foot syndrome. Pol J Environ Stud. 2005;14(s2):633-5

[13] Kuwabara M, Takahashi TA, Nagahata H et al. Spin-trapping detection of superoxides in polymorphonuclear leukocytes stimulated with serum-opsonized zymosan. Jpn J Vet Res 2000;48(1):3-13.

Submitted: 25 May, 2009 Accepted after reviews: 14 August, 2009 